SISTEMA
ELETROANICO
DE REVISTAS
SER I UfPR

\title{
Retornar à Terra no Antropoceno: estamos atrasados?
}

\section{Return to Earth at the Anthropocene: Are We Too Late?}

\author{
Raphael Bezerra VIANNA ${ }^{1 *}$ \\ ${ }^{1}$ Programa de Pós-Graduação em Meio Ambiente, Universidade do Estado do Rio de Janeiro (UERJ), Rio de Janeiro, RJ, Brasil. \\ *E-mail de contato: raphaelvmb@gmail.com
}

Ensaio recebido em 2 de janeiro de 2017, versão final aceita em 3 de outubro de 2017.

RESUMO: O objetivo deste ensaio é atentar para algumas controvérsias que acompanham a chegada dessa nova época, particularmente no Brasil, e destacar a presença de três diferentes grupos na matriz discursiva do Antropoceno: os aceleracionistas, os ecomodernistas e os Terranos. Esclarecer o que está em disputa nesse tempo não parece fácil. É diante desse desafio que proponho a seguinte questão: estamos atrasados?

Palavras-chave: Antropoceno; terranos; ecologia política.

ABSTRACT: The aim of this essay is to draw attention to some controversies that accompany the arrival of this new age, particularly in Brazil, and to highlight the presence of three different groups in the discursive matrix of the Anthropocene: the accelerationists, the ecomodernists and the Earthbound. It does not seem easy to clarify what is in dispute at this time, and it is due to this challenge that I propose the following question: are we too late?

Keywords: Anthropocene; earthbound people; political ecology. 


\section{Emaranhados no Antropoceno}

A influência humana no curso das dramáticas transformações ambientais do período pós-Segunda Guerra, com a Grande Aceleração do Século XX (Steffen et al., 2011), corroborou para a ocorrência de uma série de descontinuidades espaço/temporais equiparáveis aos eventos geológicos. Origina-se, daí, a sugestão da chegada de uma nova época denominada como o Antropoceno. Para Paul J. Crutzen, um dos propositores do termo, na ausência de uma catástrofe global como, por exemplo, o impacto de um meteorito ou uma pandemia, a humanidade permanecerá como a principal força ambiental por milênios (Crutzen, 2002; 2010). O termo Antropoceno sugere, portanto, dois fatores, a saber: i) a Terra está se movendo para outra época geológica; ii) a atividade humana é largamente responsável por essa saída do Holoceno, o que prediz que a humanidade adquire o caráter de uma força geológica global (Steffen et al., 2011).

O trabalho de Waters et al. (2016) aponta diferenças funcionais e estratigráficas entre o Holoceno e o Antropoceno - a partir da investigação de depósitos antropogênicos em sedimentos e amostras de gelo. Os autores observam a presença de concreto e de diferentes tipos de plásticos, assim como as assinaturas geoquímicas com elevados níveis de hidrocarbonetos poliaromáticos, bifenilas policloradas, resíduos de pesticidas e acréscimos nas taxas de chumbo, em virtude da queima de gasolina - iniciando entre 1945 e 1950 . No estudo também foram considerados outros fatores, como os depósitos de radionuclídeos artificiais; as extinções e as invasões de espécies biológicas; o aumento do nível do mar acima das taxas do Holoceno tardio; e o aumento da temperatura média global acima da variação Holocênica.

Steffen et al. (2011), por sua vez, observam uma importante variabilidade da concentração por volume de $\mathrm{CO}_{2}$ atmosférico: em 1750 era de 277 partes por milhão (ppm); 279 ppm em 1775; 283 ppm em 1800 e 284 ppm em 1825. Até aqui, todas as concentrações observadas se inserem na variação Holocênica de 260 - 285 ppm. Apenas em 1850 a concentração de $\mathrm{CO}_{2}$ atmosférico foi até o limite Holocênico (285 ppm) e aumentou, para além de tal limite, em 1900 com 296 ppm. Em outubro de 2016, quando comparada com o mesmo mês do ano anterior, a concentração por volume de $\mathrm{CO}_{2}$ atmosférico, no observatório de Mauna Loa, Havaí, foi de 401.57 ppm; enquanto que em 2015 foi de $398.29 \mathrm{ppm}^{1}$. Estes são, portanto, alguns elementos que anunciam no horizonte um evento dotado de potência geológica: uma raridade no que tange à nossa imprecisão atual para prever, com alguma exatidão, os eventos geológicos de elevada magnitude.

Contudo, o - complicado - estado de coisas não é suficiente para oficializar o Antropoceno, e assim começam a se desdobrar as inúmeras controvérsias acerca da formalização dessa nova época. Se por um lado o Antropoceno pode ser uma oportunidade para a recusa da velha dicotomia entre Natureza e Humanidade, que estaciona a ciência e a política desde o modernismo (Latour, 2014); por outro lado, com alguma frequência, o termo é utilizado de maneira a evitar o comprometimento mercadológico de setores industriais específicos,

${ }^{1}$ Disponível em:< http://www.esrl.noaa.gov/gmd/ccgg/trends/>. Acesso em: nov. 2016. 
notadamente quando estes reivindicam o nascimento do Antropoceno em um período que antecede ao empreendimento em larga escala de suas atividades. Para lidar com essa dinâmica conflitante, a Comissão Internacional de Estratigrafia (ICS), um comitê da União Internacional das Ciências Geológicas (IUGS) — que, por sua vez, é responsável pela definição oficial da escala geológica — , criou um grupo de trabalho com a função de investigar a possibilidade de formalização dessa nova época na história geológica da Terra.

Todavia, as querelas seguem se desdobrando na medida em que vai ficando cada vez mais evidente que os esforços empreendidos para alcançar um estágio moderno não fizeram, senão nos emaranhar as coisas em um tal ponto que nem o mais eficiente sistema de fusos de um tear parece ser suficiente para desembaraçar; e esta é a complexa situação que temos de lidar: "quanto mais avançamos no tempo, menos fica possível distinguir a ação humana, o uso das técnicas, a passagem pelas ciências e a invasão da política" (Latour, 2016, p. 63). E, assim, se vai expandindo uma nebulosa onde as controvérsias e os acordos possíveis passam a demandar um novo nível de exigência, ao que aqui entendo como um retorno à Terra.

Para indicar esse chamado de volta à Terra, será destacada a ocorrência de uma guerra para, em seguida, trazer as controvérsias que se colocam quando da presença de três grupos - seguramente uma simplificação - na matriz discursiva dessa nova época, sempre que possível enfatizando algumas particularidades do cenário brasileiro. São eles: o grupo que concebe o crescimento econômico como o destino inexorável de todos os povos da Terra, aqui denominados, em uma referência à Grande Aceleração, como os aceleracionistas; o grupo que concebe o Antropoceno como um tempo que demanda soluções majoritariamente técnicas para o controle daquilo que fora amplificado com o auxílio tecnológico, aqui referidos como os ecomodernistas; e os Terranos, grupo que resiste à dominação dos refúgios da Terra, assim definido, cabe dizer, por uma interpretação pessoal do termo proposto por Bruno Latour (2014, p. 23): os "Terranos que vivem no Antropoceno".

\section{A Terra inexorável: reconhecer a guerra para evitar a barbárie}

Por que, então, diante das tantas evidências que atestam que a Terra já não é suficiente para suprir o crescimento econômico atual, ainda parecemos atolados na lama que nos impede de experimentar outros possíveis?

Evidentemente que não há, aqui, uma resposta para essa pergunta, o que não impede o exercício reflexivo. O Filósofo Michel Serres, na obra intitulada "O contrato natural" (1990, pp. 11 - 14), descreve - inspirado na obra "Lucha con palos", do pintor espanhol Francisco de Goya - dois inimigos que brandiam os seus respectivos varapaus sobre a areia movediça. Na medida em que a luta se acirra, a areia parece ganhar terreno sobre os corpos dos lutadores. A dúvida sobre quem sairá vencedor ou perdedor paira sobre os apostadores que, inebriados diante do espetáculo banal, negligenciam, assim como os lutadores, o lento movimento do substrato inconsolidado sobre o qual chafurdam igualmente sem perceber. Nesse lento movimento, as chances seriam maiores para aquele que aposta em quem vai perder: incluídos os apostadores! Ora, nessa batalha, quem parece ganhar terreno senão o pântano? Co- 
mo nos indaga Serres (1990, p. 12) "em que areias movediças nos atolamos em conjunto, adversários ativos e espectadores perigosos?".

Trata-se, afinal, de uma aposta perigosa, pois se ganharmos, seguiremos no curso da história mesma que nos traz as evidências de uma Terra hostil aos nossos empreendimentos ávidos por crescimento; mas, se perdermos, estaríamos, nesse momento, despreparados para uma catástrofe. Astúcia, ainda com Serres, é apostar na nossa responsabilidade, já que nesse caso, se perdermos, estaríamos na condição mesma da primeira aposta, mas se ganharmos, ganharíamos muito mais do que os ganhos históricos nos proporcionaram até agora em termos de uma "Terra reativa" (tomo emprestado o termo de Isabelle Stengers) que inverte, de maneira nada sutil, a perspectiva de pertencimento: a Terra inexorável. Em tempo: diante da tela de Goya, com algum esforço, pode-se designar os dois inimigos pela suas posições.

O antropólogo Arturo Escobar (2015) observa que, a atual pressão sobre os territórios em nível mundial pode ser entendida como uma verdadeira guerra contra os mundos de ontologias relacionais - ontologias onde os humanos e os não-humanos preexistem às relações que os constituem - e, portanto, uma guerra contra os mundos relacionais, com a intenção de desmantelar todo o coletivo (Escobar, 2015). Assim, o que se põe em questão no Antropoceno é uma guerra pelo controle do mundo que habitamos coletivamente (Latour, 2014), e que coloca um número crescente de modos de vida sob o amálgama da multiterritorialidade; i.e., a complexificação de múltiplos processos de reterritorialização (Haesbaert, 2014, p. 85). É nesse cenário que emergem os diversos conflitos gerados pelo avanço do que Escobar (2015) denominou como a ontologia dualista - pois dicotômica - da modernidade, que atingiu a sua máxima expressão com a globalização.

Agora, como observa Latour (2002), ser global se tornou um problema a ser resolvido, uma vez que a solução para os conflitos (a Natureza unificada: o mononaturalismo da Razão) já não está mais disponível como nos tempos da modernização: já não é mais possível pacificar as paixões através de um sólida importação de fatos indiscutíveis. Todavia, se por um lado existem problemas causados pela unificação globalizante, a fragmentação também começa a se tornar problemática: a fragmentação parte o mononaturalismo e a homogeneização vela as ontologias relacionais; e as contradições e batalhas começam a aparecer de ambos os lados.

Estamos, pois, nessa perspectiva, diante de uma Guerra dos Mundos, onde a paz da modernidade - que não reconhecia a existência de conflitos potenciais para além de manifestações das representações culturais - já não é capaz de resolver. Esclarecer, então, a existência de uma guerra, torna-se crucial para alcançar a paz em um mundo a ser composto progressivamente, sem ser idealizado e sem que seja forçado o abandono de ontologias. Portanto, trata-se de pensar sobre o trabalho diplomático a ser realizado no lugar de continuar falando sobre progresso, modernidade e desenvolvimento sem perceber o preço que poderá ser pago para alcançar tais objetivos (Latour, 2002, p. 3). Se "desde o momento em que entramos no multiverso, temos que lidar com a guerra dos mundos" (Latour, 2016, p. 161), descobrir as maneiras de compor o multiverso mostra-se como um dos maiores desafios políticos e também científicos, de nosso tempo. A ecologia política ganhando relevância, na medida em que os territórios são colocados em risco, é um 
sintoma desse momento onde a ciência e a política necessitam caminhar com precaução e sob passos sincronizados, i.e., quando múltiplas entidades reivindicam sua consideração na composição política.

Logo, e acompanhando Danowski \& Viveiros de Castro (2015, p. 122), o que se coloca “[...] em disputa na controvérsia ambiental são posições onde os atores estão politicamente implicados, onde alguns têm tudo a perder e outros muito a ganhar [...]". E assim, ainda com os autores (2015, p. 117), a questão ambiental confere "à essa guerra um caráter de urgência, colocando-nos a todos diante do imperativo de determinarmos na prática quem são esses "todos", contra quem exatamente essa guerra está se travando, e de que lado "nós" estamos" [aspas deles]. Comecemos por aqueles que negam os laços que fazem os "nós".

\section{Certo Antropoceno brasiliano: os aceleracionistas, o arco do desmatamento $e$ a flecha do tempo}

A Organização das Nações Unidas para a Alimentação e a Agricultura (FAO), observa que o agronegócio gerou quase $70 \%$ do desmatamento na américa Latina e no Caribe, no período entre $2000-2010$, e atenta para o papel preponderante da conversão de florestas em pastagens no caso brasileiro, onde mais de $80 \%$ do desmatamento estava relacionado com essa atividade no período entre os anos de 1990 e $2005^{2}$. Mas, "Ambientalistas, deem licença! O Brasil precisa crescer", com esse título, uma matéria veiculada em 20 de dezembro de 2016, ganhava destaque no site oficial da Frente Parlamentar da Agropecuária ${ }^{3}$. Quando da ocorrência da Conferência do Clima da Organização das Nações Unidas, em Marrocos, em novembro de 2016, o Ministro Brasileiro da Agricultura fora questionado sobre as suas declarações que diziam respeito ao compromisso assumido pelo Brasil no Acordo Climático de Paris, no final de 2015. Em resposta concedida ao Jornal "Estado de São Pau1o"4. , o Ministro colocou:

\begin{abstract}
"É intenção. Não é a agricultura e a pecuária que tem de pagar essa conta. As metas são metas gerais que o Brasil colocou e ali deu uma indicação de por onde pode sair, mas se não cumprir através de reflorestamento ou de melhoramento de pastagem, vai ter de fazer em outro lugar. Não é obrigação da agricultura. Não queiram pendurar essa conta no setor agrícola sozinho."
\end{abstract}

A controvérsia se desenvolve em um momento em que a produtividade do agronegócio vislumbra alcançar o recorde de 11 milhões de hectares na área plantada com lavouras até 2024/2025 (MAPA, 2015). E, assim, o avanço da fronteira agropecuária tensiona o arco do desmatamento e lança a flecha do tempo (entropia) em distâncias cada vez mais profundas na Amazônia ${ }^{5}$ e nos demais biomas

\footnotetext{
${ }^{2}$ Disponível em: <http://www.fao.org/americas/noticias/ver/pt/c/425810/> Acesso em abr. 2017.

${ }^{3}$ Disponível em: <http://www.fpagropecuaria.org.br/destaques/ambientalistas-deem-licenca-o-brasil-precisa-crescer\#.WF1skGUkiOM>Acesso em: abr. 2017.

${ }^{4}$ Disponível em: < http://sustentabilidade.estadao.com.br/blogs/ambiente-se/para-blairo-maggi-metas-brasileiras-para-o-clima-sao-so-intencao/> Acesso em: abr. 2017.

${ }^{5}$ Segundo o Instituto Nacional de Pesquisas Espaciais (INPE), a taxa de desmatamento anual (km2/ano) da na Amazônia Legal, no ano de 2015, foi de 6.207, um aumento de 24\% em comparação ao ano anterior (2014); o acumulado no período 1988-2015 é de $413882 \mathrm{~km} 2 /$ ano. Disponível em: <http://www.obt.inpe.br/prodes/prodes_1988_2015n.htm>. Acesso em: out. 2016.
} 
brasileiros. Não o faz sem o preguiçoso uso do fogo ${ }^{6}$ para transformar as florestas em paisagens de pastos e monoculturas entediantes de Organismos Geneticamente Modificados (OGM) embebidos em agrotóxicos ${ }^{7}$, e, com alguma frequência, utilizando uma força de trabalho análoga à escravidão. Se "o Brasil precisa crescer", esse discurso esconde, portanto, a ferocidade de suas propostas, já atenuadas pela promessa de riqueza universal. Não se trata, pois, de um argumento errante, mas ancorado, no caso ao qual aqui interessa, à uma agenda prescritiva que traz à tona a vontade de outros atores, ao que tudo indica, igualmente comprometidos com o desenvolvimentismo.

\subsection{O mal Antropocênico e a prescrição desenvolvimentista}

Consideremos, em um breve exercício pedagógico, o Antropoceno como um mal; sejamos ousados: um tumor. Ora, de maneira geral, uma das primeiras preocupações após a amarga notícia é saber se estamos lidando com um tumor benigno (apenas assim, eu penso, a utilização do termo "bom Antropoceno" pode começar a fazer algum sentido) ou um tumor maligno (um mau Antropoceno). Não pretende-se aqui fornecer tal diagnóstico, mas a título de investigação, examinemos o caso brasileiro de negligência para com o mal Antropocênico que, como ocorre com muitos tumores, não cessa de crescer. Alimentá-lo, portanto, é a controvérsia para a qual se busca aqui atentar.

É possível dizer que as investidas, que hoje causam algum espanto, já estavam anunciadas, em 2015, numa "Agenda Brasil"" - que propôs uma série de medidas para a retomada do crescimento econômico, dentre as quais aqui destaco: a revisão da legislação de licenciamento de investimentos em áreas protegidas; a simplificação do licenciamento para a construção de equipamentos e infraestrutura em Unidades de Conservação; a simplificação dos procedimentos de licenciamento ambiental; e a revisão dos marcos jurídicos que regulam as terras indígenas, de maneira a permitir a compatibilização do setor produtivo.

Logicamente que tal agenda torna-se mais palatável com o auxílio de uma série de docilizações. No caso brasileiro, a oferta de emprego se revela como um argumento irrecusável - e compreensível - já que a taxa de desocupação (desocupação/ força de trabalho x 100), no último trimestre de 2016 , foi de $11,9 \%$ (12, 1 milhões de pessoas $)^{10}$. Tal fato confere, ao capital, um vasto terreno para

${ }^{6}$ O Portal do Monitoramento de Queimadas e Incêndios do INPE demonstra que no ano de 2017 - até o dia 14/09/2017 - a ocorrência de focos de queimadas foi contabilizada em 139.618, o ano com maior número de focos na série histórica de sete anos considerada no Portal. Disponível em: <http://www.inpe.br/queimadas/situacao-atual> Acesso em: ago. 2017.

${ }^{7}$ Segundo o Dossiê emitido pela Associação Brasileira de Saúde Coletiva (ABRASCO, 2015), um terço dos alimentos consumidos cotidianamente no Brasil está contaminado por agrotóxicos.

${ }^{8}$ Segundo o Ministério do Trabalho e Emprego (MTE, 2014), as atividades que mais concentraram trabalhadores em situações análogas à escravidão foram a pecuária (40\%); a produção florestal (25\%); e a agricultura (16\%). Disponível em: <http://acesso.mte.gov.br/trab_escravo/ portaria-do-mte-cria-cadastro-de-empresas-e-pessoas-autuadas-por-exploracao-do-trabalho-escravo.htm>. Acesso em: set. 2017.

${ }^{9}$ Disponível em: <http://www12.senado.leg.br/noticias/materias/2015/08/12/agenda-brasil> Acesso em: dez. 2016.

${ }^{10}$ Disponível em: <http://saladeimprensa.ibge.gov.br/noticias.html?view=noticia\&id=1\&idnoticia=3351\&busca=1\&t=pnad-continua-novembro-taxa-desocupacao-foi-11-9>. Acesso em: dez. 2016. 
a deslocalização por intermédio do que Phillipe Pignarre e Isabele Stengers denominaram de "alternativas infernais", i.e., alternativas que se impõem em distintas situações, de maneira que não causem muito alarde, mas que possam minar a capacidade de pensar e de resistir daqueles aptos a fazê-lo (Stengers, 2015, p. 55 - 56).

Isto pode se traduzir na barganha, para que as atividades com elevado potencial degradador possam se inserir em lugares fecundos ao desenvolvimento de seus negócios. Assim, uma alternativa infernal - de fácil identificação - é a garantia de degradação ambiental ou o desemprego. Não é estranho que, após a catástrofe causada em decorrência da atividade mineradora em Mariana, estado de Minas Gerais, um grupo de moradores, cuja maioria era formada por funcionários da empresa responsável pelo ocorrido, foi às ruas solicitando a retomada das atividades de mineração para garantir a continuidade dos fluxos econômicos ${ }^{11}$. Aqui, a leitura de Giorgio Agamben (2007, p. 70) - inspirado em Walter Benjamin, que coloca o capitalismo como a religião da modernidade - pode clarear esse problema, uma vez que como religião, atenta o autor, o capitalismo apresenta um caráter cultual, cuja liturgia é o trabalho, o elemento que adoça com surpreendente efetividade o discurso desenvolvimentista no atual cenário político do Brasil: "não vamos falar em crise, vamos trabalhar"12 - convoca- va o então Presidente interino, quando da cerimônia de posse de seus novos ministros.

O discurso desenvolvimentista, no entanto, nas poucas vezes que fala em crise ambiental, geralmente o faz com o auxílio de "pequenas hipnoses" (Vaneigem, 2002) que azeitam os mecanismos para a consagração do neocapitalismo ecológico, que pinta o óleo, o metal e as cinzas com o verde, que também é a cor do dinheiro ${ }^{13}$. Os investimentos em programas socioambientais por parte dos conglomerados da degradação - ainda que observadas as boas intenções de muitos cientistas que deles participam - são um importante ato, onde "o que não pode ser usado acaba, como tal, entregue ao consumo ou à exibição espetacular" (Agamben, 2007, p. 71), ao que denomino aqui por encanto ambiental. Tal encanto confere à degradação ambiental o status de um mal necessário, e não o faz sem garantir alguma passividade com o precioso auxílio da exibição espetacular.

Seguramente que trata-se de uma hipótese tão ampla quanto passível de ajustes, pois provisória, mas esses conglomerados funcionam conforme a economia do Holoceno - aquela cuja expansão nos levou ao Antropoceno - e se o lucro for ameaçado em qualquer instância, não é absurdo suspeitar que os trabalhadores e os projetos ambientais serão diretamente prejudicados - quiçá dispensados -, o que deixaria carecendo de proteção os ecossistemas,

\footnotetext{
${ }^{11}$ Disponível em: <http://g1.globo.com/minas-gerais/noticia/2015/11/protesto-em-apoio-samarco-e-feito-em-frente-prefeitura-de-mariana. html>. Acesso em: dez. 2015.

${ }^{12}$ Disponível em: <http://www2.planalto.gov.br/presidente-em-exercicio/discursos/discursos-do-presidente-em-exercicio/discurso-do-presidente-da-republica-michel-temer-durante-cerimonia-de-posse-dos-novos-ministros-de-estado-palacio-do-planalto> Acesso em: jul. 2016.

${ }^{13}$ Adaptado do original de Vaneigem (2002, p. 15). O autor refere-se a emergência do "mercado de afeto - uma indústria que extrai lucros do coração", onde antigos mecanismos de poder "trabalham sob outras cores, a verde, por exemplo, que é também a cor do Dólar". Logo, "o novo consumismo pode ser democrático assim como brincalhão, mas sempre apresenta sua conta, e obriga que seja paga”.
} 
outrora "protegidos" por tais projetos, e poderia alimentar o clamor de retorno à plenitude dessas atividades degradadoras por aqueles que, por falta de opções - leia-se outros possíveis -, necessitam se colocar em marcha com o modelo exportador de commodities para aderir à economia de um Mercado (no singular, com "M" maiúsculo; "másculo" inclusive) já familiarizado por metáforas zoomórficas (Guattari, 2012, p. 46), uma vez que que dotado de "musculatura" e até de certo humor, na condição de que não seja contrariado.

O problema é que este Mercado, quando acessível, é grande demais para a Terra; e quando inacessível pode assumir a forma de "reterritorializações conservadoras de subjetividade" (Guattari, 2012, p. 13). Benefícios secundários dessa promoção: além da reserva de mão-de-obra (e de votos?), um cenário próspero aos negócios de geoengenharia.

\subsection{A tecnofilia ecomoderna}

Um fato recorrente entre o grupo dos ecomodernistas é o de tomar as técnicas de geoengenharia como a solução para os problemas ambientais, mas, com alguma frequência, sem problematizar as possíveis consequências de tal utilização para o coletivo: há "um Manifesto Ecomodernista" (Asafu-Adjaye et al., 2015, p. 18) que afirma, por exemplo, que a urbanização, a intensificação agrícola, a aquicultura, a energia nuclear e a dessalinização são processos, que demonstram a redução da dependência direta dos humanos sobre os ecossistemas. Recentemente, a Diretora de Políticas de Combate ao Desmata- mento do Ministério do Meio Ambiente (MMA) e vice-presidente do painel do clima da Organização das Nações Unidas (ONU), Thelma Krug, expôs a seguinte controvérsia:

implementar tecnologias complicadas e que não estão amadurecidas $[\ldots]$ e isso ter uma implicação na vida das pequenas ilhas [...] também é uma preocupação moral. É um dilema. Eu tenho muita sensibilidade com a questão de geoengenharia hoje. E não sou só eu. O IPCC tem preocupação até em tratar esse tema. Mas é a questão do dilema $[\ldots]^{14}$.

O Painel Intergovernamental para as Mudanças Climáticas (IPCC, 2014, p. 433-435) atenta para os riscos da ampla utilização das tecnologias que pretendem gerar emissões negativas de $\mathrm{CO}_{2}$, com o exemplo mais notável das denominadas tecnologias de Captura e Armazenamento de Carbono (CCS). Em tese, ainda que balizado por um número limitado de estudos, o que não assegura, conforme aponta o IPCC, a eficácia dessas tecnologias, as CCS's poderiam suplantar outras formas de mitigação (como o reflorestamento) e, em virtude de uma possível redução nas concentrações de $\mathrm{CO}_{2}$ na segunda metade do século, poderia intensificar a emissão por parte de alguns setores industriais que tradicionalmente já emitem grandes quantidades de $\mathrm{CO}_{2}$, mas em um curto intervalo de tempo ${ }^{15}$. Estaríamos portanto, nesse cenário, sob a ameaça de uma intensa investida territorial por parte dessas indústrias. Por outro lado, o IPCC (2014, p. 422) possui uma passagem especialmente importante no que tange a base mercadológica de suas recomenda-

\footnotetext{
${ }^{14}$ Disponível em: <http://www.observatoriodoclima.eco.br/relatorio-sobre-15oc-trara-dilema-moral/>. Consultado em: nov. 2016.

${ }^{15}$ Tal descrição não é inédita e foi inspirada na reflexão, vale dizer, muito bem detalhada de Daniel Tanuro. Disponível em: $<$ http://www.inprecor.fr/article-Climat-Le\%20spectre\%20de\%201a\%20géo-ingénierie\%20hante\%201'accord\%20de\%20Paris?id=1867>. Acesso em: jun. 2016.
} 
ções, quando aponta que os seus modelos utilizam as bases econômicas para a tomada de decisão e assumem o pleno funcionamento dos mercados e o comportamento competitivo que os caracterizam, o que incentiva, mesmo que indiretamente, a emergência de "soluções" como as tecnologias CCS's.

Não se trata aqui de incentivar a tecnofobia, mas, como sugeriu Guattari (2015, p. 394), de pensar a apropriação da tecnologia através de ações políticas específicas com peso para cambiar as orientações aterradoras do crescimento econômico atual. $\mathrm{O}$ autor observa a importância de considerar as mutações científicas, tecnológicas, estéticas e maquínicas em um sentido amplo. Afinal, o movimento reacionário à máquina pode servir de argumento para os conservadorismos, as fobias e as reterritorializações perigosas. Trata-se, portanto, esta reflexão, menos de uma prescrição do que de uma sinalização à "tecnologia popular" (Bookchin, 2010, p. 98-99), a saber, técnicas descentralizadoras que possam favorecer a autonomia das pessoas e das comunidades face às técnicas concentradoras de riquezas e mantidas através de des-reterritorializações sucessivas, cujo exemplo emblemático no Brasil é a construção do complexo - para geração de energia hidrelétrica de Belo Monte, em Altamira, no Pará. Para o Ministério de Minas e Energia, "a construção de Belo Monte atende aos interesses do governo brasileiro de produzir energia limpa, renovável, sustentável e eficiente, para assegurar o seu desenvolvimento econômico e social" ${ }^{16}$. Para as famílias originalmente ocupantes das áreas que serão alagadas quando do funcionamento da Usina foram oferecidas duas alternativas: i) as indenizações; e ii) o reassentamento distante do rio. A primeira seria incompatível com a especulação fundiária crescente na região pela chegada do empreendimento; a segunda distanciaria as famílias de seus modos de vida tradicionais ligados ao rio ${ }^{17}$.

Ao que parece, a modernização progride por rompimentos de laços que formam um estranho paradoxo: nós já um tanto desatados. Nós, que nos achamos modernos, se assim seguirmos, eu desconfio, jamais seremos Terranos, isto é, continuaremos nos convencendo de que estamos sozinhos no Mundo, ainda que não estejamos; e tampouco estivemos. Para retornar à Terra não há uma fórmula universal, assim como não parece haver em lugar algum. Mas ainda assim, há lugares em que novos laços podem inspirar outros nós.

\section{Os múltiplos Terranos}

Se, especialmente para o caso brasileiro, existem grupos que pretendem controlar o Antropoceno através de investidas territoriais de caráter entrópico, isto não é feito sem que haja resistência. Uma passagem oriunda da Carta Aberta da Sociedade Civil Brasileira na $13^{a}$ Conferência das Partes da Convenção da Diversidade Biológica e seus Proto$\operatorname{colos}^{18}$, assinada por 58 atores - entre associações, articulações, movimentos, campanha, comissões, coordenações, fóruns, fundações, grupos, centros, instituto, núcleos de pesquisa, redes, sindicatos,

\footnotetext{
${ }^{16}$ Disponível em: <http://www.mme.gov.br/web/guest/destaques-do-setor-de-energia/belo-monte> Acesso em: ago. 2017.

${ }^{17}$ Informação obtida no Dossiê Belo Monte do Instituto Socioambiental. Disponível em: <https://www.socioambiental.org/sites/blog.socioambiental.org/files/dossie-belo-monte-site.pdf>. Acesso em: jul. 2016

${ }^{18}$ Disponível em: <http://terradedireitos.org.br/wp-content/uploads/2016/11/CARTA-DE-POSICIONAMENTO-SOCIEDADE-CIVIL-PARA-COP-13-MOP-8-MOP-2.pdf> Acesso em: nov. 2016
} 
sociedades e organizações -, em 05 de novembro de 2016, parece corroborar esse argumento:

"Entendemos que o cumprimento das metas de Aichi [para conter a perda de biodiversidade mundial], especialmente as referentes à conservação e uso sustentável da biodiversidade, está intrinsecamente associada à garantia de acesso dos agricultores, povos indígenas, povos e comunidades tradicionais à terra e ao território tradicionalmente ocupados [...]".

Em uma entrevista, recentemente traduzida para a língua portuguesa, Michel Foucault (2015, p. 99) comenta que "se não houvesse resistência, não haveria poder [...] as relações de poder aludem, de um lado, à vontade de impor algo e, de outro, ao desejo de resistir". Nesse caso, "as tensões podem ser fortes ou visíveis ou implícitas, e assim por diante". Assim, "é no campo das resistências, mais ou menos fortes, que constituem uma sociedade". Contudo, "a resistência não pode mudar nada se nas formas pelas quais as pessoas resistem ao poder não há uma nova forma de organização, de relações, de relações sociais, de ideologia do saber, e assim por diante". É evidente que isso traz o problema de um novo diálogo entre essa multiplicidade; suscita o desafio de que isso ocorra sem a "tentativa de reorganizar o mesmo poder apenas como uma mudança de titular" (Foucault, 2011, p. 78). Para iluminar tal problema, examinemos, ainda que de maneira resumida, a noção dos agenciamentos coletivos.

Um agenciamento é o "crescimento das dimensões numa multiplicidade que muda necessariamente de natureza à medida que ela aumenta suas conexões" (Deleuze \& Guattari, 2011, p. 24).
Guattari (2013) observa que os agenciamentos coletivos temem a instalação de leis fundadas sobre a hierarquia de essências transcendentes e preferem conferir à si as suas leis em função das contingências históricas e das singularidades que lhes são inerentes. Os agenciamentos coletivos podem até despejar leis gerais, mas que, em virtude de seu caráter transitório, serão substituídas diante de outras leis e outros agenciamentos. Para Guattari, portanto, os comportamentos das multiplicidades implicam agenciamentos que

associam, mais além do que as relações das pessoas, órgãos de grupos, processos econômicos, materiais e semióticas de todo tipo. Por não estar equipado por leis transcendentes e por representantes da lei, por não estar dispostos da maneira de (bi)dipolos objeto-sujeito [...] ditos agenciamentos constituem o lugar onde se refugia tudo o que há de vivo no socius (Guattari, 2013, p. 109).

Para Donna Haraway (2015, p. 160), existe a possibilidade de que o Antropoceno seja um evento-limite, marcado pela destruição de espaços-tempos de refúgios para as pessoas e outros seres; isto é, uma Terra repleta de refugiados, humanos e não-humanos, sem refúgios. Um problema imposto por um evento-limite que evoca um "conceito-limite" que põe em crise radical os princípios do Estado-nação (Agamben, 2007, p. 30), a saber, o refugiado. Portanto, se o que está colocado em disputa são distintos modos de vida, pode-se suspeitar que, na medida em que vão sendo descritas as entidades que compõem os territórios $^{19}$, pode emergir a noção de refugiados em potencial, um conceito-limite que

\footnotetext{
${ }^{19}$ Segundo o xamã yanomami Davi Kopenawa "na floresta, a ecologia somos nós os humanos. Mas são também, tanto quanto nós, os xapiri [espíritos], os animais, as árvores, os rios, os peixes, o céu, a chuva, o vento e o sol!"; "Nascemos no centro da ecologia e lá crescemos"; "Nós falamos de urihi a, a terra-floresta, e também dos xapiri, pois sem eles, sem ecologia, a terra esquenta e permite que epidemias e seres maléficos se aproximem de nós!” (Kopenawa \& Albert, 2015, p. 480).
} 
talvez possa colaborar no esclarecimento do estado de Guerra dos Mundos - uma condição para que a paz seja negociada (Latour, 2002).

Logo, para saber com quem formar alianças agora que o acordo sobre o Universo não é mais feito sem resistência (Latour, 2016, p. 208), parece ser necessário debruçar-se sobre o enigma do multiverso: menos do que formar perigosos fronts com bandeiras ao vento "em nome da Terra", retomar a nossa existência Terrestre, como aqui se quis sugerir, é o exercício de descobrir aquilo que nos une e que, portanto, não podemos viver sem. Menos um fim do que novos meios.

\section{Conversação}

O Antropoceno, independente de sua formalização, aqueceu o clima do debate contemporâneo sobre a interferência humana no funcionamento do planeta. Ocorre que a Terra extrapolou o limite da Razão que, esvaziada de sua potência unificadora, perdeu o controle sobre a ordem e a homogeneidade: temos de lidar com uma Terra excêntrica, pois desterritorializada dos territórios dicotômicos da Razão. É aqui que descobrir o que nos une em teias de interdependência se torna uma exigência, que parece cada vez mais vital; e tal tarefa não será fácil. Não há uma solução pavimentada, é preciso descobrir o que é pertencer à Terra, e as ciências têm um papel importante nesse fazer.

Evidentemente que isso traz implicações de ordem epistemológica; mas os refugiados em potencial não parecem estar aguardando a orientação de especialistas - e nem teriam tempo para tal! Nesse caso, é de grande relevância que os cientistas e o público interessado nas questões ambientais, inclusive a título de aprendizado, lancem olhares para as diversas "lutas ontológicas" (Escobar, 2015) que, em vanguarda, resistem - com a Terra - "à [...] dissolução [ecocida] pelo liquidificador modernizante" (Viveiros de Castro, 2015, p. 15). Afinal, seria um equívoco acreditar em uma Ciência daqui purificada dos problemas de lá. Lembro: a água represada de lá também ilumina os pensamentos daqui.

Os abusos que nos levaram ao/trouxeram $o$ Antropoceno sugerem que será a Terra a detentora da palavra final sobre a pretensa soberania do determinismo econômico; por outro lado, suspeito que será com essa mesma Terra que será composta, e aqui me inspiro em Agamben, a politica que vem. Daí a contribuição da ecologia política, para que seja possível exibir os territórios indispensáveis às formas-de-vida e, então, criar outros possíveis onde os esforços para a dominação dos refúgios na Terra se tornem um abuso intolerável, pois para Ela já parece ser (eis o Antropoceno). Entre tecnófilos e aceleracionistas que pensam em escapar rumo ao Universal e tecnófobos elou chauvinistas inebriados por nostalgias que convidam ao sufocamento cosmopolítico, suspeito que é chegada a hora de descobrirmos o meio: retornar à Terra. Reconheço que esse será um processo desafiador e lento, mas ampliá-lo sugere-se inadiável. Estamos atrasados? O silenciamento dos espaços finitos indica que sim.

\section{Referências}

ABRASCO. Dossiê ABRASCO: um alerta sobre o impacto dos agrotóxicos na saúde. Carneiro, F. F. (Org.). Rio de Janeiro: EPSJV; São Paulo: Expressão Popular, 2015. Disponível em: <http://www.abrasco.org.br/dossieagrotoxicos/ wp-content/uploads/2013/10/DossieAbrasco_2015_web. pdf > Acesso em: set. 2017.

Agamben, G. Profanações. Trad. Selvino José Assmann, 
São Paulo: Boitempo, 2007.

Asafu-Adjaye, J.; Blomqvist, L.; Brand, S.; Brook, B.; DeFries, R.; Ellis, E.; Foresman, C.; Keith, D.; Lewis, M.; Lynas, M.; Nordhaus, T.; Pielke, R.; Pritzker, R.; Roy, J.; Sagoff, M.; Shellenberger, M.; Stone, R.; Teague, P. An ecomodernist Manifesto. 2015. Disponível em: < http:// www.ecomodernism.org >. Acesso em: set. 2018.

Bookchin, M. Ecologia social e outros ensaios. Mauro José Cavalcanti (Org.), Rio de Janeiro: Achiamé, 2010.

Crutzen, P. Geology of mankind. Nature, Vol. 415, 23, 2002. doi: $10.1038 / 415023 a$

Crutzen, P. Anthropocene man. Nature, Vol. 467, s10, 2010. doi: $10.1038 / 467 \mathrm{~S} 10 \mathrm{a}$

Danowski, D.; Viveiros de Castro, E. Há mundo por vir? Ensaio sobre os medos e os fins. Florianópolis: Cultura e Barbárie: Instituto Socioambiental, 2015.

Deleuze, G.; Guattari, F. Mil Platôs. Capitalismo e esquizofrenia, Vol. I. Trad. Oliveira, A.L.; Neto, A.G; Costa, C.P. $2^{\mathrm{a}}$ ed. São Paulo: Editora 34, 2011.

Escobar, A. Territórios da diferença: a ontologia política dos “direitos ao território". Desenvolvimento e Meio Ambiente, 35, 89-100, 2015. doi: 10.5380/dma.v35i0.43540

Foucault, M. Microfisica do poder. Roberto Machado (Org., Int., Rev. Tec.). 29ª Ed. São Paulo: Edições Graal, 2011.

Foucault, M. "O poder e a política de Michel Foucault". Trad. André Degenszajn. Revista Ecopolítica, 12, 93-107, 2015. Disponível em: $<$ https://revistas.pucsp.br/index.php/ ecopolitica/article/view/24625

Guattari, F. Caosmose. Trad. Oliveira, A.L.; Leão, L. C. $2^{\text {a }}$ ed. São Paulo: Editora 34, 2012.

Guattari, F. Líneas de Fuga. Por otro mundo de posibles. $1^{a}$ ed. Trad. Pablo Ariel Ires. Cidade Autónoma de Buenos Aires: Cactus, 2013.

Guattari, F. Qué es la ecosofia? Textos presentados y agenciados por Stéphane Nadaud. $1^{\mathrm{a}}$ ed. Trad. Pablo Ariel Ires. Cidade Autónoma de Buenos Aires: Cactus, 2015.

Haesbaert, R. Viver no limite: Território e multi/transterritorialidade em tempos de in-segurança e contenção. 1. ed.
Rio de Janeiro: Bertrand Brasil, 2014.

Haraway, D. Anthropocene, Capitalocene, Plantatiocene, Chthulucene: Making Kin. Environmental Humanities, 6, 159-165, 2015. Disponível em: <http://environmentalhumanities.org/arch/vol6/6.7.pdf

IPCC, 2014: Climate Change 2014: Mitigation of Climate Change. Contribution of Working Group III to the Fifth Assessment Report of the Intergovernmental Panel on Climate Change [Edenhofer, O.; R. Pichs-Madruga; Y. Sokona; E. Farahani; S. Kadner; K. Seyboth; A. Adler; I. Baum; S. Brunner; P. Eickemeier; B. Kriemann; J. Savolainen; S. Schlömer; C. von Stechow; T. Zwickel; J.C. Minx (eds.)]. Cambridge University Press, Cambridge, United Kingdom and New York, NY, USA. Disponível em: < http://www. ipcc.ch/pdf/assessment-report/ar5/wg3/ipcc_wg3_ar5_full. pdf $>$. Acesso em: set. 2017.

Kopenawa, D.; Albert, B. A queda do céu: Palavras de um xamã yanomami. $1^{\mathrm{a} E d}$. Trad. Beatriz Perrone-Moisés. São Paulo: Companhia das letras, 2015.

Latour, B. War of the worlds. What about peace? Chicago: Prickly Paradigm Press, LLC, 2002.

Latour, B. Para distinguir amigos e inimigos no tempo do Antropoceno. Revista de Antropologia, 57(1), 11-31, 2014. Disponível em: <http://www.revistas.usp.br/ra/article/ view/87702>

Latour, B. Cogitamus: seis cartas sobre as humanidades científicas. São Paulo: Editora 34, 2016.

MAPA - Ministério da Agricultura, Pecuária e Abastecimento. Projeções do agronegócio - Brasil 2014-2015 a 2024-2025, 2015. Disponível em: < http://www.agricultura.gov.br/arq_editor/PROJECOES_DO_AGRONEGOCIO_2025_WEB.pdf >. Acesso em: out. 2016.

Serres, M. O contrato natural. Lisboa: Instituto Piaget, 1990.

Steffen, W; Grinevald, J; Crutzen, P.; Mcneill, J. The Anthropocene: conceptual and historical perspectives. 2011. Disponível em: <http://rsta.royalsocietypublishing.org/ content/369/1938/842> . Acesso em: 09/12/15.

Stengers, I. Catastrophic times. Resisting the coming barbarism. Open Humanities Press. 2015. Dis- 
ponível em: <http://meson.press/wp-content/uploads/2015/11/978-1-78542-010-8_In-Catastrophic-Times Stengers.pdf $>$. Acesso em: 28/11/15.

Vaneigem, R. A arte de viver para as novas gerações. São Paulo: Conrad Editora do Brasil, 2002.

Viveiros de Castro. E. O recado da mata. In: Kopenawa, D.; Albert, B. A queda do céu: palavras de um xamã Yanomami. $1^{\mathrm{a} E d}$. Trad. Beatriz Perrone-Moisés. São Paulo: Companhia das letras, 2015. p. $11-41$.
Waters, C. N.; Zalasiewicz, J.; Summerhayes, C.; Barnosky, A. D.; Poirier, C.; Uszka, A. G.; Cearreta, A.; Edgeworth, M.; Ellis, E. C.; Ellis, M.; Jeandel, C.; Leinfelder, R.; Mcneill, J. R.; Richter, D.; Steffen, W.; Syvitski, J.; Vidas, D.; Wagreich, M.; Williams, M.; Zhisheng, A.; Grinevald, J.; Odada, E.; Oreskes, N.; Wolfe, A. P. Anthropocene is functionally and stratigraphically distinct from the Holocene. Science, 351(6269), 137-148, 2016. doi: 10.1126. 